\title{
El análisis de los sistemas políticos latinoamericanos
}

Gonzalo Varela

A partir de una crítica del enfoque que privilegia la explicación economicista, el autor se propone un análisis eminentemente político de los sistemas latinoamericanos.

\section{I}

$\mathrm{L}$ a interpretación de la realidad latinoamericana vive en tensión. Por un lado enfrenta el desafio que le plantean las intuiciones universalistas de los autores clásicos del pensamiento social. Recordemos (por dar sólo algunos ejemplos) a Marx y su creencia en la posibilidad de un conocimiento objetivo; o a Max Weber, con su conocida afirmación de que la sociología debía ser capaz de formular proposiciones de validez universal; por no hablar de Tocqueville, para quien "las diferencias que sirven como punto de partida de su reflexión no son nunca reducidas a singularidades históricas, a pesar de que él atribuya la mayor importancia a la historia de los pueblos que estudia".' Por otro lado nos asedia la exigencia celosa y apasionada de crear "una teoría nuestra", aplicable a las especificidades latinoamericanas y alejada de modelos rechazados tanto por su adaptación forzada como por ser supuestamente portadores de pretensiones culturales hegemónicas. La crítica se deja así tentar por el empirismo o el historicismo o, sino, por generalizaciones tan perezosas como cargadas de impli-

${ }^{1} C f r$ artículo sobre Tocqueville, en Raymond Boudon y Franfois Bourricaud, Dictionnaire critique de la sociologie, Presses Universitaires de France, París, 1982. Sobre los aciertos y limitaciones de estas visiones universalistas, también R. Boudon, "Will sociology ever be a normal science?", en Theory and society, vol. 17, núm. 5 , 1988-89. 


\section{SECUENCIA}




caciones ideológicas. En la práctica-por extraño que parezca- ambas inclinaciones pueden también combinarse en una sola obra o en el pensamiento de un mismo autor. Es poco, sin embargo, para culpar de estos vicios a los anteriormente citados, que se esforzaron por enlazar en su obra lo general con lo particular: recordemos de paso las superficiales pero agudas impresiones de Marx sobre España, ${ }^{2}$ o la labor pionera de Tocqueville y Weber como fundadores de una sociología histórica que aún hoy sigue pugnando por un pleno reconocimiento. ${ }^{3}$

Otro lastre radica en la reticencia de muchos autores de la región a desarrollar un análisis específicamente político. El hecho de que las más habituales y fecundas perspectivas de investigación, comúnmente influidas por el marxismo o por el estructural-funcionalismo, se hayan fijado en los problemas del desarrollo económico o de la modernización cultural, generó una obsesión economicista o sociologista que embarga incluso a quienes se han preocupado por rescatar el tema político. ${ }^{4}$ No me refiero al

${ }^{2}$ El análisis de Marx sobre España como sociedad europea atípica, contiene más reflexiones sugerentes para el estudio de América Latina que sus escasos y pobres escritos sobre esta misma región. Vease, por ejemplo, la relación inversa que establece, en la historia española del siglo XIX, entre acción de clase y activismo militar en política. Karl Marx y Federico Engels, Revolución en España, Ariel, Barcelona, 3" ed., y José Arico, Marx y América Latina, Alianza Editorial Mexicana, México, 1982, 2" ed., pp. 170-177.

"Charles Tilly, "Future history", en Tbeory and society, op. cit.

4 Véase más adelante la crítica a Guillermo A. O'Donnell, Modemización y autoritarismo, Paidós, Buenos Aires, 1972, y también Fernando Henrique Cardoso, "Sobre la caracterización de los regímenes autoritarios en América Latina", en David Collier (comp.), El nuevo autoritarismo en América reconocimiento de la importancia de la estructura y la dinámica económicosociales en la explicación de la política -que permanece como otra de las intuiciones más rescatables de la sociología-sino a una visión esencialista de las clases, la economía o el desarrollo, que postula expresa o tácitamente la imposibilidad o la banalidad de una reflexión específica sobre procesos e instituciones políticas.

Buscamos en este trabajo hacer una crítica de este tipo de enfoque, para ensayar a continuación -a mero título demostrativo- un ejercicio de construcción de una tipología basada en conceptos políticos, que sirva para ubicar y analizar los distintos sistemas políticos existentes en los países latinoamericanos.

\section{II}

Tomemos un ejemplo conocido de la dificultad de manejo de la información empírica e histórica sobre los sistemas políticos latinoamericanos, de acuerdo con parámetros teóricos que obstaculizan el pleno desarrollo de un análisis propiamente político. Me refiero a la inclusión que hizo Guillermo O'Donnell de México dentro de su modelo de régimen burocrático-autoritario, a la vez que excluía de la misma categoría al gobierno militar peruano del general Juan Velasco Alvarado.

Latina, Fondo de Cultura Económica, México, 1985, que propone practicamente una reducción del concepto del Estado al de dominación de clase.

'Cfr. Guillermo A. O'Donnell, op. cik, cap. 2 y especialmente nota en pp. 106-108, y también "Reflexiones sobre las tendencias de cambio del 
Recuérdense las hipótesis básicas del autor: a) existe correlación entre el nivel de modernización de las sociedades latinoamericanas y el tipo de régimen político ${ }^{6}$ prevaleciente; $b$ ) a dichos efectos, no deben compararse las sociedades globales sino sus áreas modernizadas; $c$ ) los países latinoamericanos de mayor modernización relativa tienden a tener regímenes autoritarios y no democráticos.

Hasta aquí el análisis se mantiene en un ámbito tal de generalidad que hay poca objeción que pueda hacérsele. Pero otra cosa sucede cuando se consideran las estructuras políticas concretas y los sistemas institucionales de los países que supuestamente cuadrarian con la clasificación de regímenes burocráticoautoritarios.

O'Donnell diseñó su modelo de régimen burocrático-autoritario como correlato político de situaciones de modernización relativamente avanzada, marcadas por: a) políticas públicas de concentración económica y política; $b$ ) coaliciones de poder determinadas por una alianza del estado, el capital nacional y

\footnotetext{
Estado burocrático-autoritario", en Revista Mexicana de Sociología, núm. 1, 1977. No se trata aquí de hacer una crítica global de la obra de O'Donnell -que por demás constituye un aporte de innegable valor- sino de ilustrar ciertos problemas de interpretación teórica. Una visión de conjunto deberia abarcar las sucesivas elaboraciones y rectificaciones que el autor ha añadido. Para un balance, D. Collier, op. cit., Karen L. Rernmer y Gilbert W. Merkx, "Bureaucratic authoritarianism revisited", Latin American Researcb Review, núm. 2, 1982.

- Posteriormente O'Donnell prefiri6 hablar de "Estado" y no de "régimen", G. A. O'Donnell, "Reflexiones...", y 1966-1973. El Estado burocrático-autoritario. Triunfos, demotas y crisis, Belgrano, Buenos Aires, 1982.
}

el capital internacional, y $c$ ) mecanismos de desactivación y exclusión de la participación popular. En esta descripción calzaban adecuadamente los gobiernos militares de Argentina (1966-73) y Brasil (1964-84) que eran aquellos que mejor conocía el autor y en los que se' baso para construir su teoría. Pero luego afirmó que ésta era generalizable a aquellos países latinoamericanos que enfrentaran una etapa avanzada de modernización, lo que le hizo contemplar los casos problemáticos de Perú y México.

En el aspecto del control militar del Estado el Perú de 1968-75 se asemejaba a Argentina y Brasil, pero por su escaso grado de modernización, así como por sus políticas encaminadas a la ampliación y protección del mercado interno y por la coalición de poder, abierta a la participación popular, parecía acercarse a los clásicos gobiernos populistas de Getulio Vargas en Brasil (1930-45) y de Juan Domingo Perón en Argentina (19461955). Por su parte México vivía una etapa de modernización avanzada, pero su régimen corporativo no producía aparentemente las condiciones de exclusión popular necesarias para ser catalogado como burocrático autoritario en la acepción de O'Donnell.

Éste salvó el inconveniente con un doble paso. Por un lado trivializó el componente militar como elemento importante en la caracterización de los regímenes políticos. Supuso que, con base en su búsqueda de incorporación de sectores populares y el tipo de coalición en que se apoyaba, el régimen militar peruano podia catalogarse como "autoritarismo populista”. Por otro lado afirmó que la coalición y las políticas públicas imperantes en México eran las mismas 
que las de los regímenes burocráticoautoritarios, por lo que este país encajaba en el modelo. Sólo quedaba un obstáculo: que en México no se daba la exclusión por vía coercitiva del sector popular que consideraba propia de los regímenes burocrático-autoritarios. Para salvar el inconveniente, O'Donnell, que hasta el momento se había regido por los criterios de incorporación versus exclusión, forjó sobre la marcha una tercera categoría, la de "encapsulamiento" del sector popular, que produciría, por otras vías, resultados similares a los de la exclusión.

Veamos ahora, en este caso clásico, cómo cristalizan algunas de las contradicciones teóricas ya apuntadas: ${ }^{7}$

Primero, el estructuralismo economicista. El concepto de área modernizada juega el papel de una estructura socioeconómica en que se disuelven las diferencias políticas. Por la misma razón, el análisis político tiende a resumirse en el económico-social.

Segundo, en el plano estrictamente político se confunde el concepto de sistema institucional ("régimen") con el de dominación ("coalición").

Tercero, desde el punto de vista lógico se confunde igualdad de causas con igualdad de efectos, al suponer que las mismas coaliciones de actores dominantes dan el mismo tipo de régimen, y que los mismos regímenes dan el mismo tipo de políticas públicas. ${ }^{8}$

7 Y en lo relativo a México, véase la crítica de Julio Labastida, "Proceso político y dependencia en México (1970-1976)", en Revista Mexicana de Sociologia, op. cit.

- Téricamente, iguales causas deberian producir iguales efectos. Pero como los factores
Cuarto, lo anterior bloquea el desarrollo de una sociología centrada en las estructuras e instituciones políticas, su génesis, su funcionamiento y su relación con el ambiente social y económico, de donde surge una concepción excesivamente abstracta del estado. ${ }^{9}$

De este modo no se explican algunos curiosos desfases históricos propios de la región, implícitos en el examen de casos que acabamos de ver:

1. Pueden existir similitudes políticas entre países, no obstante diferencias socioeconómicas notables. En la segunda mitad de los años sesenta Argentina, Brasil y Perú presentaban índices de modernización radicalmente distintos: elevados los dos primeros y bajo el tercero. Sin embargo, el proceso que conduce a la instalación del gobierno militar peruano de 1968 tiene cierto paralelismo con el que antecedió a los golpes de 1964 y 1966 en Brasil o Argentina: movilización de masas, incapacidad de las estructuras políticas existentes para canalizarlas, veto conservador al acceso al gobierno de fuerzas políticas con apoyo popular (peronismo y aprismo) y, finalmente, arbitraje militar. La diferencia radica en que, una vez instalado el régimen militar peruano, su política es muy distinta a la de los otros dos, puesto que mientras éstos son

causales abstraídos por los modelos teóricos interactúan en la realidad empírica con una gama variable e indeterminada de otros factores, esta ley no siempre se cumple. Cabe aclarar, por otra parte, que en Modemización y autoritarismo el autor no habla de determinación causal, sino de "correlato político", lo que daría la idea de interdependencia; pero en los hechos unilateraliza el análisis.

- Esta se hace patente en G. A. O'Donnell, 1966-1973. El Estado..., cap. I. 


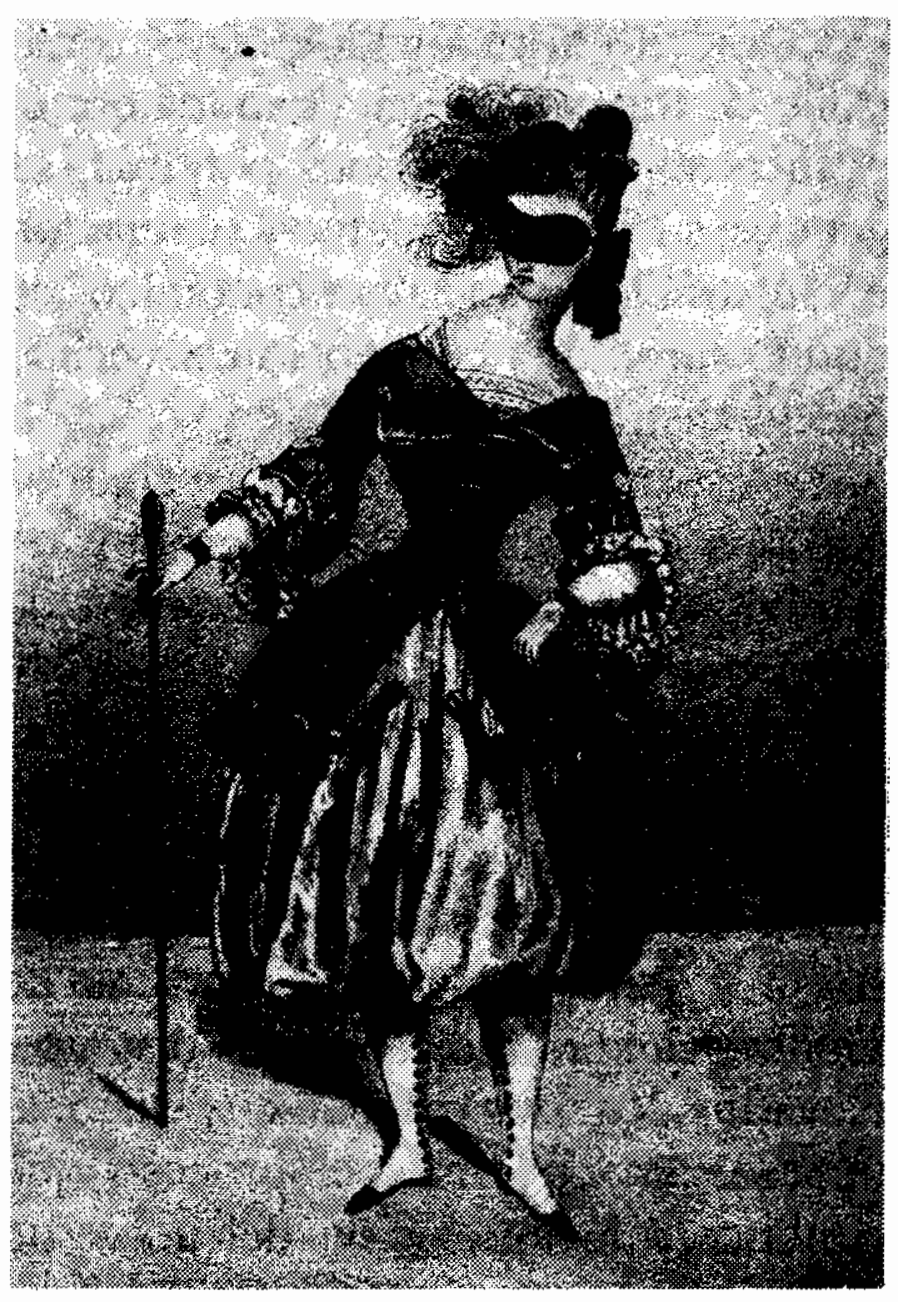

excluyentes de los intereses populares, la de los peruanos apunta a la redistribución del ingreso y a la puesta en marcha de mecanismos de intermediación corporativa del tipo que Juan Linz y Alfred Stepan califican de "estatismo orgánico". ${ }^{10}$ Esta variación es efectivamente explicable por las diferencias en el grado de modernización del Perú, que hacian factible ensayar alli políticas populistas que en otros países ya se habían probado y agotado. Obsérvese que en este nivel de interpretación necesitamos efectivamente recurrir, como postula O'Donnell, a la relación entre

10 Juan Linz, "Totalitarian and authoritarian regimes", en Fred Greenstein y Nelson Poslby (comps.), Handbook of political science, AddisonWesley, Massachussets, 1975, vol. 3, y Alfred Stepan, The state and society. Peru in comparative perspective, Princeton University Press, New Jersey, 1978. modernización socioeconómica y dinámica política, pero sólo después de haber comprobado que la misma es más flexible e indeterminada de lo que supone el modelo.

Ello nos permite no trivializar el componente militar de los regímenes, sino darle su peso específico. $\mathrm{El}$ mismo no deriva de la vinculación constante y uniforme con una determinada coalición de poder o con la aplicación de determinadas políticas públicas. Como observa Samuel Huntington, los militares, como institución, no cumplen siempre el mismo papel político: suelen ser progresistas en sociedades tradicionales y conservadores en sociedades desarrolladas. ${ }^{11}$ Pero en ambas alternativas su intervención pude estar determinada por la debilidad (típicamente sudamericana) de sistemas políticos en que no hay una firme hegemonía establecida, lo que redunda en "pretorianismo de masas $^{\text {"12 }}$, inestabilidad institucional y arbitraje castrense. ${ }^{13}$ Así, lo que aproxima a los regímenes militares (al menos en su fase emergente) son una serie de fenómenos más políticos que socioeconómicos: movilización de masas, bloqueo a la participación popular, fragmentación de fuerzas, arbitraje militar.

2. Inversamente, pueden existir heterogeneidades políticas entre países con grados de desarrollo y estructuras socioeconómicas muy similares: Brasil y

" Cfr. Samuel P. Huntington, El orden político en las sociedades en cambio, Paidós, Buenos Aires, 1972.

${ }^{12}$ Según la expresión del mismo Huntington.

13 Pero no se entiende aquí arbitraje en el sentido de neutralidad, sino de capacidad de mediar autoritariamente entre actores en conflicto. 
México. Aun aceptando que ambos tuvieran coaliciones dominantes y politicas públicas similares en las décadas de los años cincuenta y sesenta -cuando sufren un fuerte impulso modernizadorlas diferencias en cuanto a estabilidad política son evidentes. El desfase nos aleja nuevamente del nivel de explicación socioeconómica para centrarnos en la singularidad histórico-política, producida en México por la revolución, con la destrucción de la antigua clase y el antiguo régimen oligárquicos, y la canalización de la movilización popular en estructuras de apoyo al nuevo estado que luego habrían de servir también como molde para contener las fuerzas movilizadas por el proceso de modernizador.

3. Un tercer tipo de desfase lo vemos en algunos países de América Central en nuestros días. Consiste en una modernización del papel político y técnico de las fuerzas armadas que no guarda correspondencia con la realidad de sociedades poco modernizadas en lo económico y social. Los casos más característicos son los de El Salvador y Guatemala, donde con motivo de la guerra civil o de la lucha antisubversiva, el aparato militar se ha profesionalizado y tecnificado en forma creciente, a la vez que ha asumido la tutela de un sistema político basado en sistemas partidarios inestables y fragmentados.

En varios aspectos el proceso es similar a los conocidos en América del Sur. En lo que tiene que ver con una modernización de las fuerzas armadas relativamente mayor que la de la estructura de clases o la del resto de las instituciones públicas, se aproxima a la situación de algunos países ...1dinos como Bolivia,
Ecuador o Perú. En lo que se relaciona con el papel político de los militares, se reproduce también el ciclo de erosión y persistencia de la dominación oligárquica, incapacidad de las viejas estructuras políticas para incorporar la movilización de masas, inestabilidad y, finalmente, activación y reforzamiento de las fuerzas armadas como garantes del orden. El militarismo, en su forma moderna, ya sea como gobierno directo o como tutela del sistema político ejercida no por un caudillo sino por un aparato burocrático, es un resultado del vacío dejado por la decadencia de anteriores formas de dominación. Pero si apelamos a la comparación de El Salvador y Guatemala por un lado, con Panamá por el otro, comprobaremos una vez más que el mismo puede dar lugar a coaliciones dominantes y políticas públicas muy diversas.

\section{III}

Partimos con una sumaria mención de las tensiones ideológicas y metodológicas que plantea a los estudios sociales y políticos latinoamericanos el problema de la relación entre lo general y lo particular, así como el desafío de las grandes teorías. Pretendimos luego examinar las disyuntivas que se desprenden de premisas interpretativas que no contemplan adecuadamente la especificidad de lo político y su efecto de retroalimentación sobre la estructura socioeconómica. Seguidamente trataremos de recoger las conclusiones y críticas esbozadas. Dado que buscamos caracterizar la estructura del sistema político, tomaremos como elementos fundamentales de definición el tipo de autoridad política 
existente y. los actores estatales dominantes en el sistema.

La autoridad implica relaciones de mando y obediencia basadas en pretensiones de legitimidad. ${ }^{14}$ Diferenciamos tres situaciones básicas, en una escala de menos a más:

Fragmentación, cuando no existe un centro institucional autónomo ni acuerdo entre las elites políticas y sociales y por tanto impera la inestabilidad, o lo que Huntington llama "pretorianismo de masas".

Arbitraje, cuando uno o más actores son capaces de imponer un "equilibrio inestable $^{n 15}$ al sistema político.

Estado, cuando existe una autoridad política centralizada, autónoma y estable. Ello implica que consideramos que no existe un Estado en sentido estricto en los casos anteriores, aun cuando hubiera algún tipo de centro institucional que fuera capaz de conservar un relativo control del territorio nacional y sus habitantes.

Por actores estatales entendemos aquellos que se constituyen especificamente en función de la gestión pública. ${ }^{16}$ Son dominantes cuando fungen

\footnotetext{
${ }^{14}$ Sobre el concepto de autoridad veanse Max Weber, Economia y sociedad, Fondo de Cultura Económica, México, 1964, 2* ed., cap. I, y Robert A. Dahl, Análisis politico moderno, Fontanella, Barcelona, 1976, cap. III.

is Sobre el concepto de equilibrio inestable, vése David Easton, "Categorias para el análisis sistémico de la política", en D. Easton (comp.), Enfoques sobre teoria politica, Amorrortu, Buenos Aires, 1969.

${ }^{16}$ Hay actores no estatales sino sociales, que pueden ser sumamente influyentes y aun dominantes en las sociedades latinoamericanas, como la Iglesia, las oligarquias y el empresariado moderno. Pero no los consideramos aquí porque nos
}

como elementos principales de apoyo y organización del sistema de autoridad política. Los distinguimos por el tipo de organización y de personal. Estos actores pueden ser:

Lospartidos políticos. Su personal dirigente lo compone una clase política ${ }^{17}$ y su organización es por lo general masiva, abierta y de tipo asociativo.

El sector corporativo de agregación y canalización de intereses de clase, preferentemente populares. Su dirigencia es de tipo gremial-sindical y su organización agrupa categorías profesionales. La afiliación puede ser obligatoria o voluntaria, pero en todo caso acotada a un número limitado de instituciones reconocidas por el estado. ${ }^{18}$

limitamos al análisis de los sistemas de autoridad política. Por otra parte suponemos que los actores sociales dominantes se expresan políticamente por medio de (o en alianza con) partidos, organizaciones corporativas y burocracias públicas. Es importante también hacer notar que la existencia de los actores estatales es algo distinto de la existencia del estado mismo. Los primeros pueden subsistir y aun jugar papeles importantes en situaciones de fragmentación o de arbitraje. Acerca de la diferencia entre actores estatales y sociales, Peter Gourevitch, Politics in bard times. Comparative responses to intemational economic crisis, Comell University Press, Ithaca-Londres, 1986. No obstante, he manejado con bastante libertad estas categorias, especialmente al restringir el concepto de partidos al de actores estatales.

17 Raymond Aron, "Clase social, clase política y clase gobernante", en Reinhard Bendix y Seymour M. Lipset (comps.), Clase, status y poder, Euramérica, Madrid, 1972, tomo II.

10 Estamos pensando en sindicatos y organizaciones profesionales en tanto fuerza de apoyo directo al estado y en ese sentido nos interesa solamente el corporativismo de tipo estatal. Sobre la diferencia entre corporativismo estatal y social, cfr. Philip Schmitter, " Continuamos en el siglo del corporativismo?", en El Buscón, núms. 13 y 14, y sobre la posible extensión de la organización corporativa a actividades sociales distintas de aque- 
La burocracia priblica civil. Su marco organizativo está dado por la misma administración pública. Se puede distinguir en su interior una burocracia de elite y otra de base, además de una gama de estratos intermedios.

Las fuerzas armadas comparten algunas características con la anterior, pero se restringen a un sector particular de la administración pública, regido por una disciplina sui géneris y que concentra el monopolio de la violencia legítima.

Podemos combinar ambas clasificaciones para desembocar en una tipología de las distintas modalidades de control político en América Latina. Ésta se esquematiza de la manera siguiente:

\begin{tabular}{|l|l|}
\hline Sistema de autoridad & $\begin{array}{l}\text { Actores estatales } \\
\text { dominantes }\end{array}$ \\
\hline Fragmentación & $\begin{array}{l}\text { Partidos } \\
\text { Burocracia militar }\end{array}$ \\
\hline Arbitraje & $\begin{array}{l}\text { Partidos } \\
\text { Sector corporativo } \\
\text { Burocracia militar }\end{array}$ \\
\hline Estado & $\begin{array}{l}\text { Partidos } \\
\text { Sector corporativo } \\
\text { Burocracia civil } \\
\text { Burocracia militar }\end{array}$ \\
\hline
\end{tabular}

Obsérvese que en este cuadro de combinaciones hay algunas exclusiones. Se da por supuesto que la presencia de un sector corporativo fuerte es incompatible con situaciones de fragmentación, y lo mismo sucede con la burocracia

llas ligadas a la producción, M.L. Harrison, Coporatiom and the welfare State, Gower, Aldershot (Hampshire), 1984, cap. 2.

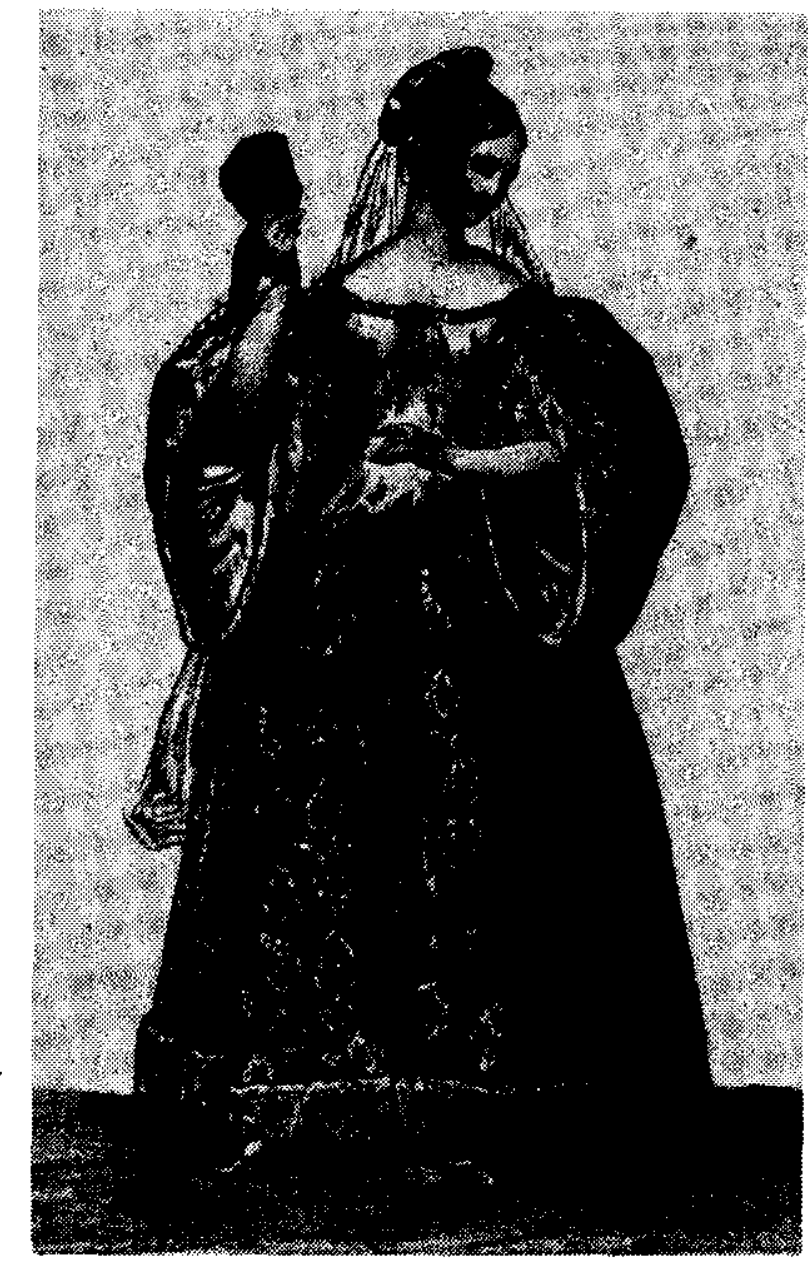

pública civil en las situaciones de fragmentación y de arbitraje. Aunque ello no sea evidente en el cuadro, también pensamos que la premisa de que el sector corporativo pueda constituirse en actor dominante no deja de ser discutible, por razones que veremos más adelante. Pero antes explicaremos la relación entre la tipología y los sistemas políticos concretos.

La fragmentación política puede coexistir con el predominio de un sistema de partidos o de una burocracia militar. El primer caso es recurrente en América del Sur, en periodos de crisis, cuando aun no se perfila una hegemonía militar, o cuando ha perdido peso. Habría ejemplos a señalar en la década de 1930 -en que la región vivió los efectos de la depresióneconómica internacional-pero también más recientemente: Brasil de 1960 a 1964, Chile de 1971 a 1973, y 
Argentina de 1973 a 1976 . El segundo caso se verifica cuando la institución militar se convierte en fiel de la balanza política pero carece de unidad interna. La inestabilidad política boliviana en tiempos modemos, ${ }^{19}$ se explica en nuestra opinión por este factor, así como también la historia argentina de la primera mitad de los años sesenta.

La situación de arbitraje puede cristalizar cuando el elemento estabilizador de la política recae en un sistema de partidos, en un sector corporativo o en las fuerzas armadas. El ejemplo más típico de la primera hipótesis parece ser Colombia durante la vigencia del pacto bipartidista que de 1958 a 1970 aseguró la rotación de liberales y conservadores en el poder, cerrando el paso a una eventual dictadura militar, pero también a la competencia de otros partidos. ${ }^{20}$ Así mismo esta situación política convive con regímenes que no llegan a constituir un Estado propiamente dicho, pero que aseguran un cierto control apoyado en

\footnotetext{
"Hablamos de tiempos modernos, para distinguir al predominio militar burocrático de la dominación tradicional basada en el gobierno personal de un caudillo que controla una máquina militar o policial poco profesionalizada. Sería el caso de Fulgencio Batista en Cuba, de la dinastía Somoza en Nicaragua, de Alfredo Stroessner en Paraguay, o de Rafael Trujillo en la República Dominicana. Es sustancialmente distinto del liderazgo que puede establecerse en el seno de un aparato militar profesional, cuando el poder del lider ( $v$. gr. Augusto Pinochet en Chile) deriva de ocupar un cargo en la cúspide burocrática y no del usufructo patrimonial del poder. Con todo, el militarismo boliviano de las décadas recientes (así como el panameño) parece a menudo ubicarse en el linde entre la dominación caudillesca y la burocrática.

${ }^{20}$ En cambio, hoy Colombia parece deslizarse hacia una siruación de fragmentación política con predominio de partidos.
}

un pacto corporativo. Son los casos de los primeros gobiernos de Juan Domingo Perón en Argentina (1946-55) y de Getulio Vargas en Brasil (1930-45). En cuanto al arbitraje militar, tiene una profusa historia en la región, dada la debilidad de las estructuras civiles. Traigamos a colación sólo un caso moderno, el ya mencionado de los países centroamericanos, en que los sistemas partidarios viven a la sombra de influyentes corporaciones militares: El Salvador, Guatemala y Panamá.

El Estado puede apoyarse primordialmente en partidos, pactos corporativos o burocracias militares. Como ejemplo de Estado de partidos ${ }^{21}$ consideramos a los regímenes estables que han funcionado (aunque con interrupciones) en el largo plazo, basados en sistemas por lo general bipartidistas. Son Costa Rica, Chile, Uruguay y Venezuela. Y como casos de Estado militar pueden tomarse los regímenes burocrático-castrenses firmemente establecidos durante el último cuarto de siglo en Brasil, Chile, Perú y Uruguay. ${ }^{22}$

México sería el caso de un Estado apoyado en un pacto corporativo, pero debemos aquí contestar el interrogante que dejamos pendiente. ¿El sector corporativo puede ser realmente el actor político dominante de un Estado.233 Paga-

${ }^{21}$ Para los efectos de este artículo, el concepto de Estado de partidos no supone un reconocimiento expreso de la ley, como sucede en algunos paises europeos; Manuel García-Pelayo, El Estado de partidas, Alianza Editorial, Madrid, 1986.

22 En cambio, la dictadura militar argentina de 1976 a 1983, pese a su extrema ferocidad, no parece haber sobrepasado el nivel de inestabilidad propio de las siruaciones de fragmentación o de arbitraje.

${ }^{23}$ Recuérdese que estamos hablando del corporativismo de tipo estatal, no social. 


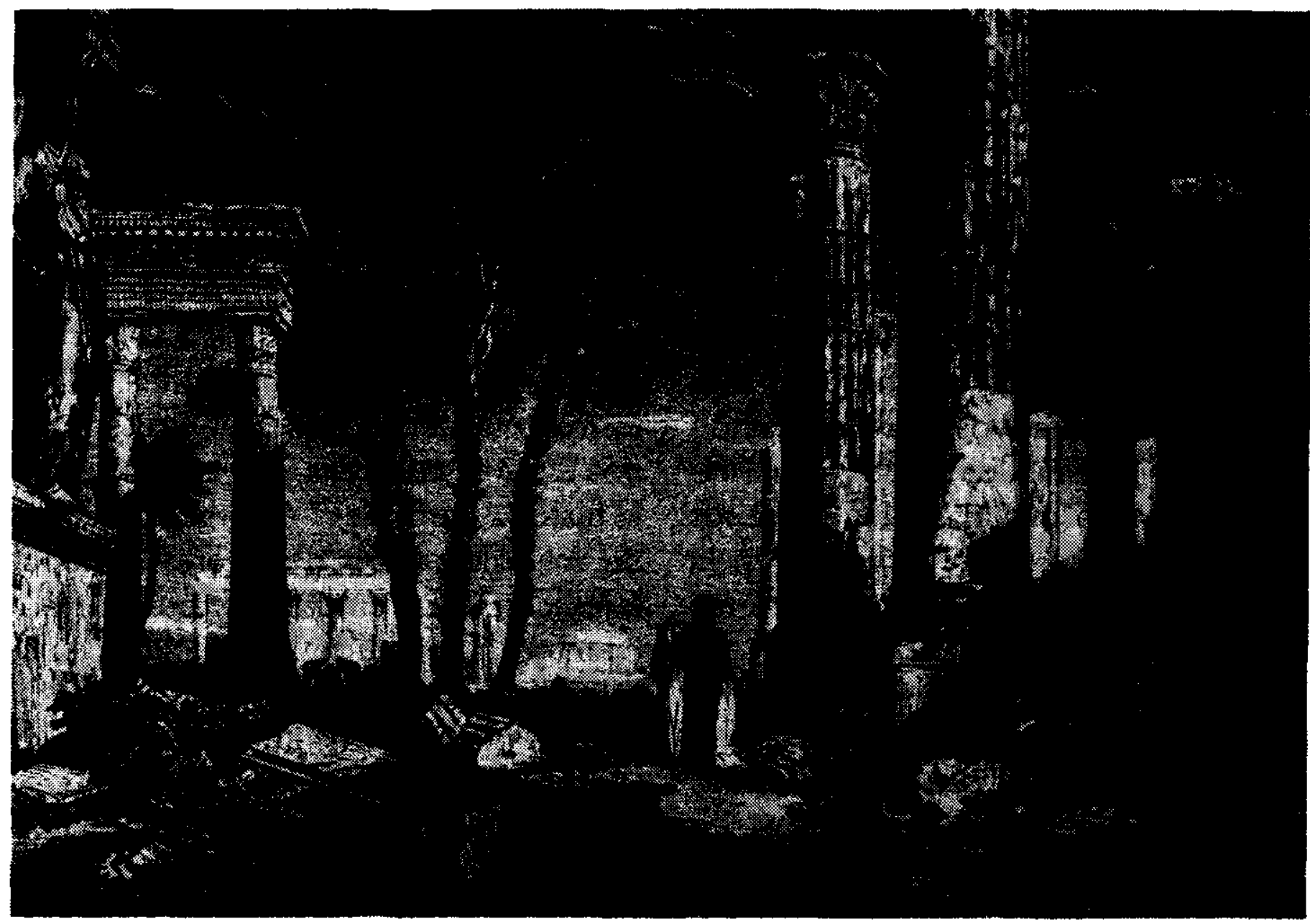

mos las consecuencias de una ambigüedad del lenguaje, pues no es lo mismo hablar de actor dominante que de actor como apoyo principal del Estado. El fondo de la cuestión reside en que la base de apoyo puede ser un elemento subordinado y no dominante. Podría argüirse que, a diferencia de los partidos, la burocracia civil, o la burocracia militar, que pueden ser alternativamente subordinados o dominantes, la organización corporativa es por definición un mecanismo de sujeción de las categorías productivas a otro actor dominante, así sea un partido o una burocracia estatal. O sea, un eslabón entre la base y la cúpula y no la cúpula misma. En tal caso deberíamos concluir que el actor político dominante en el Estado mexicano sería una elite burocrática-civil. Ello nos conduce a dos reflexiones de carácter măs general.
En primer lugar, la burocracia pública civil no podría ser actor dominante más que en un sistema de autoridad política en que el Estado hubiera logrado un alto grado de legitimidad y autonomía. ${ }^{24}$ Por otra parte, si bien es necesario, por razones analíticas, señalar actores dominantes, también lo es el cuidarse de simplificaciones. Puede haber relaciones de exclusión entre distintos actores, ${ }^{25}$ pero también de asociación y hasta de

${ }^{24}$ Algunos autores restringen a esta situación el uso del concepto de Estado; véanse Bertrand Badié y Pierre Birnbaum, Sociologie de l'Etat, Grasset, París, 1979. Debemos suponer, por lo demás, que la autonomía estatal está asociada al manejo de recursos de distinto tipo: a) económi$\cos ; b)$ ideológicos y simbólicos; $c$ ) políiticos propiamente dichos (por ejemplo, la apertura a la competencia o a una mayor participación); y d) coercitivos.

${ }^{25}$ Pierre Birnbaum, "The State versus corporatism", en Politics and society, núm. 11, 1982, 
fusion, como indica el complejo entrecruzamiento de Estado, partido y sector corporativo en el sistema político mexicano. ${ }^{26} \mathrm{El}$ precio de la consolidación de un actor dominante $o$ de la neutralización de un rival, bien puede ser el reconocimiento o la alianza con un tercero. Pensemos en el intento del régimen militar peruano de constituir mecanismos corporativos; en la relación entre líder carismático, sector corporativo y respaldo militar en los primeros gobiernos de Perón y Vargas; o en la relación entre aparato militar y sistema partidario en América Central.

\section{IV}

Hemos apenas revisado algunas de las múltiples perspectivas de análisis de los sistemas políticos latinoamericanos. Quisiéramos subrayar, para concluir, un tema relevante que si no es privativo de la región, tiene por lo menos en ésta una particular vigencia.

Se trata de la contradicción entre el papel central que se atribuye al Estado en las sociedades en desarrollo y la inestabilidad política que es una constante en la mayoría de ellas. Por ilógico que parezca, ambos problemas se refuerzan recíprocamente. El papel central del sector público en el desarrollo lo recarga de tensiones y demandas que si no son en sí mismas las causantes de la inestabilidad, tampoco contribuyen a solucionarla. ${ }^{27}$

sostiene inclusive que el desarrollo estatal, lejos de apoyarse en el corporativismo, lo inhibe.

${ }^{26}$ Daniel Cosio Villegas, El sistema político mexicano, Joaquín Mortiz, México, 1972.

${ }^{27}$ Es el tipo de problema que G. A. O'Donnell en Modemización..., resume en la doble con-
Las causas de fondo de la inestabilidad son complejas de discernir y largas de enumerar, pero mencionemos a guisa de ejemplo la herencia oligárquica que en muchos países latinoamericanos ha cristalizado en sistemas económicos y políticos con escasa capacidad de integrar a las masas populares a la participación y al consumo ampliados. ${ }^{28} \mathrm{O}$ la formación y el reconocimiento tempranos (si se le compara, por ejemplo, con la historia europea) ${ }^{29}$ de organizaciones de intermediación de intereses populares como los sindicatos, que no encuentran a menudo, paradójicamente, estructuras de agregación y negociación que les permitan institucionalizarse.

Por tanto nos hacen falta no sólo estudios empíricos, sino también una teoría de las crisis y de la inestabilidad política que, apoyada en los primeros, podría generar -como sucediera anteriormente con el tema del Estado- ${ }^{30}$ una original contribución latinoamericana a la teoría general.

tradicción entre diferenciación e integración sociales por un lado, y demandas y logros por otro.

${ }^{28}$ François Bourricaud, "El ocaso de las oligarquías y la sobrevivencia del hombre oligárquico", en Aportes, núm. 4, 1967, y Juan Carlos Portantiero, La democratización del estado, CLAFH, Montevideo, 1986.

29 Coinciden en esta observación Gino Germani, Sociología de la modemización, Paidós, Buenos Aires, 1971; Torcuato S. Di Tella, Clases sociales $y$ estructuras politicas, Paidós, Buenos Aires, 1974, y Alain Touraine, Las sociedades dependientes, Siglo XXI, México, 1978.

${ }^{30}$ G.A. O'Donnell, op. cit., y Fernando Henrique Cardoso, Estado y sociedad en América Latina, Nueva Visión, Buenos Aires, 1972, y "Estado capitalista e marxismo", en Estudos Cebrap, núm. 21,1977 . La contribución de estos autores a la revitalización del Estado producida en las últimas décadas es reconocida por Peter Evans y John D. Stephens, "Studying development since the sixties", en Theory and society, op. cit. 